Revista de Dialectología y Tradiciones Populares, vol. LXXIII, n. ${ }^{\circ}$ 1, pp. 55-61, enero-junio 2018, ISSN: 0034-7981, eISSN: 1988-8457, https://doi.org/10.3989/rdtp.2018.01.001.06

\title{
La Universidad y la vida..., o cómo mantenernos vivos en medio de la neoliberalización de la Universidad
}

\author{
University and Life... Or How to Survive the \\ Neoliberalisation of the University
}

\author{
Débora Ávila ${ }^{1}$ \\ Universidad Complutense de Madrid \\ Ariadna Ayala ${ }^{2}$ \\ Université Paris-Est \\ Sergio García ${ }^{3}$ \\ Universidad Complutense de Madrid
}

\section{RESUMEN}

La presente reflexión intenta tensionar el concepto de precariedad, entendida únicamente en términos de fragilización de las condiciones laborales, para preguntarse acerca de los efectos que las recientes transformaciones experimentadas por la Universidad (y que afectan no solo al ejercicio cotidiano de nuestro trabajo, sino también a la manera en la que nos vinculamos con nuestros compañeros y estudiantes, así como a la forma en la que nos pensamos) tienen sobre el sostenimiento de nuestra propia vida, incompatible, en demasiadas ocasiones, con las nuevas exigencias del guion neoliberal.

Palabras clave: Precariedad; Neoliberalismo; Evaluación; Competencia; Deseo.

\section{SUMMARY}

This reflection seeks to challenge the concept of precarity thinly defined as the weakening of employment conditions. In so doing, the authors shed light on recent changes in the University

\footnotetext{
${ }^{1}$ Correo electrónico: deboraav@ucm.es. ORCID iD: <https://orcid.org/0000-0003-2616-7506>.

${ }^{2}$ Correo electrónico: ariadna.ayala@gmail.com. ORCID iD: <https://orcid.org/0000-0001-8020-9020>.

3 Correo electrónico: sergig07@ucm.es. ORCID iD: <https://orcid.org/0000-0002-9551-4295>.
} 
which affect not only our day-to-day work but also the way in which we relate to our colleagues and students, as well as how we think of ourselves. We are particularly interested in the effects these transformations have on the sustainability of our own lives, often at odds with the demands of neoliberal dogma.

Keywords: Precarity; Neoliberalism; Audit; Competition; Desire.

\section{NUESTRO LUGAR...}

Quienes escribimos estas líneas, trabajamos en la Universidad española. Dos lo hacemos como docentes desde hace una década, y la tercera como experta en programas de innovación pedagógica. Hasta llegar aquí, hemos compartido tiempos de contratos parciales, de becas con final en forma de abismo, de cuadraturas imposibles a final de mes, de simultanear trabajos... Algunas de estas cosas perduran hoy. $\mathrm{Y}$, sin embargo, cuando recibimos la invitación a participar en esta sección sobre la precariedad en la Universidad, lo primero que sentimos fue cierto extrañamiento. $O$ mejor dicho, una vivencia personal que nos impide identificarnos como precarias.

Los tres accedimos a nuestro trabajo en un escenario en transformación. La Universidad se debatía entre un modelo más clásico de funcionamiento (que muchas personas críticas con la Academia española han denominado de tipo feudal ${ }^{4}$ ) y la imparable neoliberalización de sus estructuras. Tuvimos la suerte de poder esquivar a las segundas. Y eso es importante hacerlo explícito, porque ninguna de nosotras ha tenido la necesidad (por el momento) de adentrarse de lleno en esa carrera hipercompetitiva y de productividad constante que exige ahora el acceso a muchas plazas de investigación y docente. Algunos acumulamos méritos en un camino pausado, desde la seguridad económica que nos daba otro empleo en el sector público, mientras que otras nos sumergíamos en el universo de la comida rápida y las grandes cadenas de ropa: recorridos que con la motivación que hace posible sostener una doble jornada de trabajo — profesional e investigadora- hicieron realidad un proyecto personal. Otras accedimos muy jóvenes a nuestra plaza, en ese formato que podría llamarse feudal y que, sin embargo, nosotras necesitaríamos matizar. Conseguimos nuestra plaza gracias al apoyo de algunos profesores, sí. Pero ese apoyo no tuvo la forma de una relación de vasallaje sino que fue por sintonía entre maneras de hacer y entender nuestra disciplina y el papel de la Universidad. En definitiva, tuvimos madrinas, pero por afinidad generosa de quienes se reconocen en lo mismo.

Así pues, sin caminos tortuosos de meritocracia neoliberal, con unas plazas académicas relativamente estables y unas condiciones laborales privilegiadas, al primer envite no nos salía escribir sobre nuestra precariedad. Es más, sentíamos desde hace tiempo bastante distancia con las plataformas de compañeros reunidos en torno a la exigencia de mejoras laborales. No tanto porque su reclamo no sea más que legítimo

\footnotetext{
${ }^{4}$ El atributo feu $d a l$ remite a las relaciones de vasallaje entre profesores consagrados y los estudiantes y doctorandos aspirantes a ser docentes e investigadores estables. Dicho vasallaje implica una cierta protección (promesa de asignación de becas, participación en investigaciones, congresos, plazas, etc.) a cambio de subordinación (inclusión de la firma del profesor consagrado en los artículos, alineamiento incondicional en caso de conflicto interno en los departamentos, etc.).
} 
(vaya por delante que la mayoría de las profesoras universitarias somos mileuristas o ni llegamos), sino porque percibíamos cierta desconexión de esas demandas con el mundo de afuera, del que nosotras hemos logrado salir, y donde para la mayoría de los trabajadores nuestros horarios y salarios y la relativa estabilidad con la que contamos constituyen un lujo.

\section{AMBIVALENCIAS: DE LA ERÓTICA A LA ANGUSTIA Y EL AGOTAMIENTO}

Sin embargo, si empezamos a pensar en un sentido más profundo esa distancia con respecto a la idea de precariedad, debemos poner inevitablemente en el centro el deseo. Nos referimos al anhelo con el que durante mucho tiempo hemos ansiado llegar a ocupar una plaza en la Universidad, pero también a la erótica que ésta sigue despertando en nosotras una vez que estamos dentro. El poder de seducción que ejerce la Universidad tiene que ver con su configuración como lugar de poder (en el sentido foucaultiano del término), pero no sólo. Esto es: resulta innegable que el reconocimiento social que lleva asociado nuestro trabajo tiene su peso a la hora de sentirnos atraídos por el trabajo que realizamos. Aunque esta concepción de la Academia como espacio de reconocimiento es bastante tradicional, tampoco está de más preguntarse cuánto hay también de ese modo de subjetivación neoliberal, que opera para lograr una identificación lo más alta posible de los sujetos con sus lugares de trabajo, mayor cuanto más alto es el nivel de cualificación (Ballatore, Rio y Murgia 2016).

Pero la erótica que desprende en nosotras la Universidad es mucho más que la de un espacio de poder. En realidad, lo que más nos apasiona de nuestro trabajo tiene que ver con esa posibilidad de estar cerca del (y producir) conocimiento. Por suerte, cada vez más hay espacios de conocimiento por fuera de la Universidad, pero aún cuesta romper con la imagen de la Academia como el lugar por antonomasia del saber. De hecho, no se trata únicamente de una cuestión de imagen. La docencia hace de nuestro trabajo un aprendizaje constante, las redes profesionales en las que nos movemos (que implican la pertenencia a grupos de investigación, asistencia a congresos y demás cruces enriquecedores) suponen un estímulo incesante, mientras que ciertas condiciones laborales permiten una continuidad y sistematicidad en nuestras investigaciones que es difícil lograr cuando éstas se llevan a cabo de forma no asalariada.

Llegados a este punto, cabe sin duda preguntarse: ¿por qué al final decidimos escribir una reflexión sobre nuestra vivencia de la precariedad en la Universidad? La respuesta tuvo primero la forma de una intuición. Y es que todo lo anteriormente dicho convive con la sensación constante de que no llegamos a lo que se supone que debemos llegar como profesoras. Sentimos pasión por muchas de las cosas que hacemos, sí. Pero al preguntarnos por el sostenimiento cotidiano de nuestras vidas, las imágenes de miedos, presiones, equilibrios imposibles, trabajos siempre por hacer y cansancio, mucho cansancio, se suceden por doquier ${ }^{5}$.

\footnotetext{
${ }^{5}$ A dar forma a estas intuiciones nos ayudaron los compañeros de la Escuela de Afuera, un espacio de aprendizaje y pensamiento cooperativo que fundamos hace algunos años, con quienes nos decidimos a compartir estos primeros balbuceos a través de talleres que organizamos en
} 
La noción de precariedad puede darnos pistas, siempre y cuando no la reduzcamos al análisis de las condiciones laborales, sino que la entendamos como una práctica de gobierno neoliberal encaminada a la construcción de una subjetividad marcada por la inseguridad vital (Lorey 2016). Así, la Universidad ha constituido una avanzadilla en la extensión social de esta precarización, gracias sobre todo al papel determinante que han adquirido los procesos de evaluación en el desarrollo de nuestro trabajo (Indocentia 2017 [2015]; Laval y Dardot 2013). Por supuesto, uno podría argumentar que la reflexión prospectiva sobre nuestro trabajo, así como los mecanismos de rendición de cuentas ante aquellos que sostienen nuestra labor, son algo deseable. Pero no es esto lo que vivimos cotidianamente en nuestros trabajos.

Así, desde hace unos años, hemos asistido a una inflación desorbitada de procesos de evaluación continua que acechan en cada rincón de nuestro hacer diario. Conforme se suceden los meses del curso, uno debe someterse a una evaluación conjunta por parte de los estudiantes y su propia facultad (en el conocido como programa Docentia), a una evaluación anual del mérito individual, a una evaluación de los grupos de investigación a los que pertenezca, a otra evaluación de los proyectos de investigación que se tengan en activo, a los cada vez más duros procedimientos de peer review que median el acceso a una publicación escrita, a sendas evaluaciones del grado y máster en el que se imparte la docencia realizada por una Agencia estatal externa (ANECA), a las que se suman, mínimo, los procesos de acreditación ${ }^{6}$ que posibilitan el acceso a una plaza con mejores condiciones laborales asociadas. Teniendo en cuenta lo intrincado y complejo de cada uno de estos procesos, prácticamente no hay mes en el que una buena parte de nuestro tiempo de trabajo no se dedique a someterse a un proceso de evaluación.

En todos ellos, la máxima siempre es la misma: uno debe probar que no para de trabajar. Y debe hacerlo en una misma dirección: la producción al peso y la alianza con el mundo empresarial. Importa el número — de publicaciones, de proyectos aprobados, de euros conseguidos, de contratos con empresas firmados-, no la calidad del trabajo. Importa que se trabajen ciertos temas (conectados con las formas neoliberales de lo social), en determinado tipo de publicaciones (las que pujan más alto en el nuevo mercado académico), en alianza con los actores convenidos (obviamente, pertenecientes a la esfera empresarial) y que el conocimiento o el aprendizaje producido tenga la capacidad de presentarse como producto para el mercado. Los distintos dispositivos de evaluación acaban siendo tan duros y omnipresentes, que sus

la primavera de 2017. Previo, se habían sucedido ricas conversaciones con quienes coordinan esta sección a raíz de la invitación a participar en ella. En nuestra maleta llevábamos además una búsqueda de respuestas que había comenzado tiempo atrás, a partir de la constatación en primera persona de todas las transformaciones que la Universidad estaba experimentando en los últimos años, y que nos había llevado a no pocos debates e intercambios con nuestras aliadas, dentro y fuera de la Academia. En parte como reconocimiento y en parte como agradecimiento infinito a la generosidad de todas las gentes que han compartido el espacio de la Escuela de Afuera, os dejamos el enlace a su web: <https://escueladeafuera.net/>.

${ }^{6}$ En el sistema universitario español, el acceso a cualquier plaza requiere, como condición previa a poder presentarse a cualquier concurso público, la superación de un proceso de evaluación por parte de una Agencia estatal independiente (ANECA) que acredita que el aspirante acumula en su haber los méritos suficientes para la categoría laboral a la que concursa. 
efectos a la hora de modular nuestra conducta son difíciles de esquivar: bien como premio por inscribirse en la senda correcta, bien como ejercicio de exposición de aquello a lo que no se ha llegado, el itinerario por el que transitar se encuentra claramente marcado.

Por supuesto, su eficacia en términos de mejora de nuestro desempeño profesional es simple y llanamente nula. No se evalúa en ningún momento la calidad (y calidez) de nuestro hacer académico. A nadie parece importarle las horas o el cuidado invertido en preparar una clase, la labor de acompañamiento que realizamos con los estudiantes, el compromiso que construimos con aquellos con los que investigamos, el minucioso trabajo de reflexión desde el que aspiramos a aportar algo a esa tierra comunal que es el saber.

Pero su capacidad de afectación en términos de producción de un tipo muy concreto de subjetividad es demoledora. El recuerdo continuo de esa evaluación nos introduce inevitablemente en una lógica de hiperproductividad y activación constante tan característica del nuevo sujeto neoliberal (Amigot y Martínez 2013; Gómez y Jodar 2013; Laval y Dardot 2013): la máxima es no parar de escribir, de publicar, de presentar tu trabajo por doquier, de postularte a cualquier tipo de convocatoria... Y puesto que esa es la exigencia, un simple vistazo a nuestro alrededor siempre nos devolverá la impresión de que podríamos hacer más. Si en la sociedad de consumo la permanente sensación de insatisfacción llenaba el carro de la compra (Bauman 2003), en la sociedad del rendimiento (Han 2012) una persistente impresión de insuficiencia sucede a cada reto culminado: la satisfacción por el trabajo hecho únicamente durará unas horas, porque al día siguiente nos esperan algunos de los proyectos en marcha que ya habíamos iniciado y en los que nos exigiremos más impacto. Nuestro día a día se convierte así en un no parar, sin tiempo para siquiera pararse a pensar qué investigamos, por qué; qué clases damos, qué relación tenemos con los alumnos; qué publicamos, cómo y dónde; ni, por supuesto, qué vida nos queda más allá del trabajo.

Paradójicamente, en todo este proceso de construcción de subjetividad por la vía de los mecanismos de evaluación, la penalización material por no llegar a los estándares exigidos pasa al menos en el caso de la universidad española, además de por la fragilización de las condiciones laborales, por la asignación de más horas de docencia $^{7}$. En este sentido, las clases dejan de ser ese lugar central de nuestra profesión, para convertirse en una especie de carga o castigo para un profesorado cada vez más inserto en labrar una trayectoria de ascenso individual. Y es que, por si no fuera suficiente la activación en términos de productividad que estos mecanismos de evaluación desarrollan, proliferan en el ámbito académico otros dispositivos dedicados a fomentar otro aspecto constitutivo de la subjetividad neoliberal: el del éxito individual y la competencia. Así, mientras se consolida el requerimiento a la firma individual de todo aquello que producimos, se multiplican por doquier portales virtuales en los que una tiene que ir exhibiendo su trabajo, a modo de red social

\footnotetext{
${ }^{7}$ A la hora de asignar la docencia anual que un profesor debe impartir, en el caso del profesorado a tiempo completo, la normativa estatal permite un cierto margen en la distribución de la carga lectiva. Así, en aquellas situaciones en las que un departamento tiene un exceso de docencia que cubrir, puede ampliar el número de horas lectivas a aquellos profesores que no cuentan en su haber con "sexenios vivos" (tramos de investigación reconocidos por la ANECA).
} 
académica desde la cual visibilizarse como la mejor. Reuniones departamentales, tribunales y demás eventos sociales ritualizan en nuestro hacer cotidiano este espectáculo desbordado de lucimiento de egos.

Abstraerse de esa vorágine es casi imposible. Intentas recordarte una y mil veces que no te importa no llegar a ser alguien (en los términos que el neoliberalismo propone) y que todos esos principios evaluados son justo lo contrario de aquello que entendemos por conocimiento. Pero todo a nuestro alrededor nos recuerda los peligros de esa apuesta. Nuestras plazas son menos precarias que afuera, pero no son un seguro de vida. Las dinámicas competitivas y productivistas se instauran y es difícil sacar fuerzas para nadar siempre contracorriente. Intentas entonces trazar alianzas para orientar esa productividad impuesta a trabajar con gentes afines, con las que producir un conocimiento que pueda tener cierto sentido político. Pero al final acabas inserto en esa misma lógica hiperproductivista, aunque al menos se logre que el impulso venga por un régimen de favores e intercambios entre aliados, mucho más estimulante y potente en términos de reflexión comprometida, pero igual de estresante y agotadora.

Las alianzas que cultivamos fuera, gracias a nuestra pertenencia a espacios de producción de conocimiento no institucionales (editoriales alternativas, redes de investigación militante...) nos permiten pensar, producir y compartir de la mano de los movimientos de transformación social. Pero habitar el umbral no es fácil, y en ocasiones ambas lógicas se cruzan. Así, cada vez que se recibe una invitación (a publicar, a acudir a una charla...), una nunca sabe si acepta por compromiso y reciprocidad política o pensando en ese currículum individual que tenemos que alimentar constantemente. En uno u otro caso, lo cierto es que se suma un grado más al agotamiento de siempre tener algo por hacer, de no poder separar las horas de trabajo de las horas de vida, de tener la sensación constante de que no es posible llegar. Esa es nuestra precariedad: el cansancio como el coste de aspirar a sostener nuestra vida y el cuidado de los nuestros bajo la presión por cumplir con las exigencias de la Universidad neoliberalizada.

\section{UNA BATALLA POR LIBRAR}

La penetración de las lógicas neoliberales en la Universidad, decíamos, pone en jaque nuestra vida, las relaciones de cooperación con nuestros compañeros, la reciprocidad como lógica de relación. Pero no solo. Al tiempo que nuestra precariedad vital se pone en juego, lo hace también el lugar social que imaginamos para la Universidad. Dicho de otro modo: las lógicas competitivas y de mercado que se han introducido no solo condicionan a quienes la habitamos, sino que redibujan la función social del conocimiento, alejándolo cada vez más de su potencia política en términos de trasformación social.

Paradójicamente, frente a la relativa facilidad con la que la Academia acoge el pensamiento crítico, la reflexión en torno a lo que (nos) está pasando en la Universidad (Ema 2013) apenas se formula más que como un leve balbuceo. Pareciera como si nombrar estas transformaciones y sus efectos fuera demasiado incómodo... O, mejor dicho, como si, de algún modo, los procesos de evaluación y competencia, y la 
instauración de una lógica de mercado fueran inevitables o, incluso, la solución (objetiva) a las lógicas feudales que se quieren dejar atrás.

No sorprende lo minoritario de esta reflexión, pues siempre ha habido batallas arrinconadas en la Universidad, en especial si tienen que ver con el replanteamiento de su función y sus modos de hacer (el papel que le damos al otro en nuestras investigaciones, la legitimidad del saber experiencial en relación al saber experto...). Pero nos preocupa especialmente este silencio cómplice por la simbiosis armoniosa que parece establecerse con la erótica académica con la que abríamos esta reflexión. ¿Cómo lidiar con un proceso de subjetivación que precisamente alimenta nuestro deseo, en tanto se preña de múltiples procesos de reconocimiento objetivo y competitivo de nuestra valía? ¿Cómo disputar la batalla contra la precarización y la presión laboral a la que nos lleva cuando nos hallamos inmersos en ese "pozo de la pasión" que el hacer intelectual nos despierta (Murgia y Poggio 2014)? En definitiva, ¿cómo trastocar las nuevas verdades neoliberales, cómo sustraerse de una Universidad que es cada vez más parte del gobierno expandido neoliberal, y hacer de ella una apuesta clara y radical por la cultura y la igualdad social (Garcés 2014)?

\section{BIBLIOGRAFÍA CITADA}

Amigot, Patricia y Laureao Martínez. 2013. "Gubernamentalidad neoliberal, subjetividad y transformación de la universidad. La evaluación del profesorado como técnica de normalización". Athenea Digital 13(1): 99-120.

Ballatore, Magali, Maria del Rio Carral y Annalisa Murgia. 2016. "Présentation. Quand passion et précarité se rencontrent dans les métiers du savoir". Recherches Sociologiques et Anthropologiques 45: 1-13.

Bauman, Zygmunt. 1998. Trabajo, consumismo y nuevos pobres. Barcelona: Gedisa.

Ema, José Enrique. 2013. "Límites y oportunidades de lo político en la universidad. La evaluación y sus tropiezos". Athenea Digital 13(1): 59-79.

Garcés, Marina. 2014. “Están los estudiantes bien preparados?”. El País 2 jul. Disponible en: <https:/ /elpais.com/elpais/2014/07/02/opinion/1404324386_448156.html>. Fecha de acceso: 20 dic. 2017.

Gómez, Lucía y Francisco Jódar. 2013. «Ética y política en la universidad española: la evaluación de la investigación como tecnología de la subjetividad". Athenea Digital 13(1): 81-98.

Han, Byung-Chul. 2012. La sociedad del cansancio. Barcelona: Herder Editorial.

InDocentia. 2017 [2015]. "Disciplinar la investigación, devaluar la docencia: cuando la Universidad se vuelve empresa". Disponible en: <http://indocentia.blogspot.com.es/2017/01/a-continuacio-vosdeixem-una-entrevista.html>. Fecha de acceso: 20 dic. 2017.

Laval, Christian y Pierre Dardot. 2013. La nueva razón del mundo. Ensayo sobre la sociedad neoliberal. Barcelona: Gedisa.

Lorey, Isabell. 2016. Estado de inseguridad. Gobernar la precariedad. Madrid: Traficantes de Sueños. Murgia Annalisa y Barbara Poggio. 2014 «Experiences of Precariousness by Highly-skilled Young People in Italy, Spain and the UK", en Lorenza Antonucci, Myra Hamilton y Steven Roberts (eds.), Young People and Social Policy in Europe: Dealing with Risk, Inequality and Precariousness in Times of Crisis. Londres: Palgrave.

Fecha de recepción: 15 de febrero de 2018* Fecha de aceptación: 4 de abril de 2018

* Las fechas de recepción y aprobación vienen referidas al conjunto de la sección TEMAS EMERGENTES. 